\title{
Cosinor Analysis of Feed Intake Cycle of Rats Fed a Zinc-Deficient Diet and the Effect of Zinc Supplementation
}

\author{
Kazuhiro Aiba, Masahiro Kimura, Shigeko SAKata, \\ Koichi Matsuda, Masae KaneKo, Satomi Onosaka, \\ Yumiko YAMAOKA and Nanaya TAMAKI* \\ Graduate School of Food and Medical Sciences, \\ Kobe-Gakuin University, Nishi-ku, Kobe 651-21, Japan
}

(Received August 24, 1996)

\begin{abstract}
Summary Rats fed a Zn-deficient diet develop a characteristic cyclic variation in feed intake (Mills et al., Am J Clin Nutr 22: 1240-1249 (1969)). A preliminary analysis (Tamaki et al., Br J Nutr 73: 711-722 (1995)) of the cyclic variations was followed with a personal computer. Cosinor analysis revealed that the cyclic period of the feed intake of male rats was $3.5 \pm 0.05 \mathrm{~d}$. The mesor, amplitude and acrophase value were $10.0 \pm 0.3 \mathrm{~g} / \mathrm{d}, 4.4 \pm 0.2 \mathrm{~g} / \mathrm{d}$ and $3.5 \pm 0.3$ radian, respectively. The cycle of body-weight change of the $\mathrm{Zn}$-deficient rats was well synchronized with that of feed intake. The parameters of the feed intake cycle had a high correlation to the corresponding parameters of body-weight change (mesor: $r=0.846$; amplitude: $r=0.771$; period: $r=0.925$; acrophase: $r=$ $0.452)$. With the supplementation of $\mathrm{Zn}(0.95-3.80 \mathrm{mg} / \mathrm{kg}$ of the $\mathrm{Zn}$ deficient diet), cyclic variations in feed intake and body-weight change were also found. The mesor, amplitude and period of feed intake cycle were in good correlation with $\mathrm{Zn}$ intake $(r=0.856, p<0.001, r=-0.804$, $p<0.001$ and $r=0.613, p<0.01$, respectively). The cycle of feed intake of the rats fed a $\mathrm{Zn}$-free diet was simulated to be: mesor $9.7 \pm 0.1 \mathrm{~g} / \mathrm{d}$, amplitude $6.5 \pm 0.1 \mathrm{~g} / \mathrm{d}$ and period $3.4 \pm 0.02 \mathrm{~d}$. The concentration of $\mathrm{Zn}$ intake given the half-maximal value of the amplitude was assumed to be $56 \pm 1 \mu \mathrm{g} / \mathrm{d}$.
\end{abstract}

Key Words zinc deficient, Cosinor analysis, feed intake, body-weight change

Zinc $(\mathrm{Zn})$ is essential for growth in animals (1) as well as man (2). Failure to grow is seen during $\mathrm{Zn}$ deficiency, together with signs such as alopecia, depigmentation of hair, dermatitis of the paw and anorexia (3). Zn deficiency impairs growth by a combination of reduced feed intake, reduced anabolic response to food and

\footnotetext{
* To whom correspondence should be addressed.
} 
increased catabolic response (4). It has also been proposed that metabolic hormones such as insulin, somatotropin, insulin-like growth factor and corticosterone may be mediating factors in impaired growth $(5,6)$.

The reduction in feed intake is accompanied by cyclic patterns of feeding and body weight in rats given a $\mathrm{Zn}$-deficient diet $(3,4,7-12)$. Mills et al. (7) proposed originally that rats fed a $\mathrm{Zn}$-deficient diet develop a characteristic cyclic variation in feed intake, which has a frequency of 3.5-4 days. Chesters et al. $(8,10)$ found that reduction of the protein content in a $\mathrm{Zn}$-deficient diet from 20 to $5 \%$ results in increased feed intake and the disappearance of the cyclical pattern of intake. When the low-protein Zn-deficient diet was supplemented with essential and non-essential amino acids, the increased variability of intake was associated with the essential amino acid content of the diet (10). Wallwork et al. (3) suggested that the levels of tyrosine and tryptophan in the plasma are correlated with the cyclic feeding pattern of the Zn-deficient group. On the other hand, the cycles result from a slow but effective feed intake caused by the energy balance in rats (10). Recently, Rains and Shay (13) proposed that the specific changes in macronutrient intake patterns may be a reflection of $\mathrm{Zn}$-mediated changes in the central control of appetite. However, the details are obscure.

In our preliminary study (14), the calculated cyclic period was $3.5 \mathrm{~d}$ for both feed intake and body-weight change in $\mathrm{Zn}$-deficient rats. In this study, we analyzed the correlations among the parameters of feed intake and body-weight change cycles separately, as well as those between the two cycles. We also found that the cyclic variations in feed intake and body-weight change were effected by supplementation of the diet with $\mathrm{Zn}$.

\section{MATERIALS AND METHODS}

Animals. Male and female albino rats (Wistar strain, weighing 100 to $150 \mathrm{~g}$ ) were housed in individual screen-bottomed cages in a room maintained at $23 \pm 1^{\circ} \mathrm{C}$ with 50\% humidity under controlled lighting conditions (lights on from 7:00 a.m. to 7:00 p.m. and lights off from 7:00 p.m. to 7:00 a.m., local time). The rats were fed a commercial stock diet (Oriental Yeast, Tokyo, Japan) and given water ad libitum for 1 week before the experiment to acclimate them to the new environment. Acclimated rats showing progressive weight gain were selected and separated into groups. The body weight and feed intake were determined daily from 9:00-11:00 a.m. The rats were given the experimental diet for 3-5 weeks and sacrificed between 9:00-11:00 a.m. under anaesthesia with diethyl ether. In the case of the $\mathrm{Zn}$ supplementation experiment, male rats (Wistar strain, weighing about $110 \mathrm{~g}$ ) were housed.

Blood samples were taken from the carotid artery into plain glass tubes and stored at $4{ }^{\circ} \mathrm{C}$ until centrifugation at $1,500 \times g$ for $20 \mathrm{~min}$. Serum samples were stored at $-20^{\circ} \mathrm{C}$ until analysis.

Diets. The compositions of the $\mathrm{Zn}$-deficient and control diets are shown in 
Table 1. Composition of the diets $(\mathrm{g} / \mathrm{kg})$.

\begin{tabular}{lcc}
\hline & Control & Zn-deficient \\
\hline Egg albumin & 200 & 200 \\
Dextrin & 637 & 637 \\
Corn oil & 100 & 100 \\
Vitamin mixture* & 11.7 & 11.7 \\
Salt mixture $(+\mathrm{Zn})^{\dagger}$ & 31.3 & \\
Salt mixture $(-\mathrm{Zn})^{\ddagger}$ & & 31.3 \\
Cellulose powder & 20 & 20 \\
\hline
\end{tabular}

*Vitamins $(\mathrm{mg} / \mathrm{kg}$ of diet) were: retinyl acetate (2.01), cholecalciferol (0.03), $\alpha$-tocopheryl acetate (58.5), menadione (60.8), thiamine hydrochloride (14.0), riboflavin (46.8), pyridoxine hydrochloride (9.4), cyanocobalamin $(0.006)$, ascorbic acid (351), D-biotin (0.23), folic acid (2.34), calcium pantothenate (58.5), $p$-aminobenzoic acid (58.5), niacin (70.2), and choline chloride (2340).

${ }^{\dagger}$ Minerals $(+\mathrm{Zn})\left(\mathrm{g} / \mathrm{kg}\right.$ of diet) were: $\mathrm{CaHPO}_{4} \cdot 2 \mathrm{H}_{2} \mathrm{O}$ (4.557), $\mathrm{KH}_{2} \mathrm{PO}_{4}$ (8.050), $\mathrm{NaH}_{2} \mathrm{PO}_{4}$ (2.927), $\mathrm{NaCl}$ (1.459), Ca-lactate (10.983), Fe-citrate (0.995), $\mathrm{MgSO}_{4}$ (2.244), $\mathrm{ZnCO}_{3}(0.034), \mathrm{MnSO}_{4} \cdot 4-6 \mathrm{H}_{2} \mathrm{O}(0.038), \mathrm{CuSO}_{4} \cdot 5 \mathrm{H}_{2} \mathrm{O}(0.009)$ and $\mathrm{KI}$ (0.003).

${ }^{\ddagger} \mathrm{ZnCO}_{3}$ was omitted from the above mixture.

Table 1. The composition of the $\mathrm{Zn}$-deficient diet was the same as that of the above control diets with the exception that $\mathrm{ZnCO}_{3}$ was not included in the salt mixture. The content of $\mathrm{Zn}$ in the $\mathrm{Zn}$-deficient diet and control diet was 0.95 and $20 \mathrm{mg} / \mathrm{kg}$ diet, respectively. In the supplementation with $\mathrm{Zn}$, different quantities of $\mathrm{Zn}$ (0, $0.95,1.43,1.90,2.85$ and $3.80 \mathrm{mg} \mathrm{Zn} / \mathrm{kg}$ of $\mathrm{Zn}$-deficient diet) were added to the Zn-deficient basal diet. The diet was in powder form and contained in a 9$\mathrm{cm}$-diameter glass jar covered with a stainless steel lid containing nine $1.2-\mathrm{cm}$ diameter holes. All rats were given the experimental diet and deionized water ad libitum.

Alkaline phosphatase. It is well-known that $\mathrm{Zn}$ deficiency results in a defect in serum alkaline phosphatase activity $(15,16)$. Alkaline phosphatase activity was measured with respect to the rate of formation of phenol from sodium phenyl phosphate (17). The absorption at $405 \mathrm{~nm}$ was measured.

Protein measurement. The protein concentration was measured with Folin phenol reagent (18), using bovine serum albumin as the standard.

Chemicals. All chemicals used were of analytical grade and were purchased from Nacalai Tesque (Kyoto, Japan) unless otherwise stated. Animal feed was obtained from Oriental Yeast.

Derivation of feed intake and body-weight change. Feed intake and bodyweight change data were analyzed by the "Cosinor" method (19). Feed intake $(F)$ and body-weight change $(\Delta B)$ at day $t$ were derived using the following equation:

$$
F(\text { or } \Delta B)=M+A \cos (2 \pi t / \tau+\phi)
$$

where $M, A, \tau$ and $\phi$ represent the mesor (the rhythm-adjusted mean), amplitude 
(maximum and minimum value from the adjusted mean), period (the length of one complete cycle) and acrophase (phase of minimum value), respectively.

The experimental data obtained were fitted to the above equation by a nonlinear least-squares method. The four parameters, $M, A, \tau$ and $\phi$, were calculated in the subroutine analysis by Marquardt's method (20) and given with the standard deviation as obtained with a personal computer (21).

Statistical analysis. Values for feed intake and body weight are expressed as mean \pm SE except the values of the rhythmometric parameters obtained by Cosinor analysis, which are expressed as mean \pm SD. One-way analysis of variance (ANOVA) was used to compare the groups. When a significance difference $(p<$ 0.05 ) was found between groups, the statistical significance of difference between values was assessed by Student's $t$-test. Correlation and regression analyses were performed for data from individual rats with a CA-Cricket Graph (Computer Associates International, USA). The kinetic data were calculated in subroutine analyses with software (21).

RESULTS

Summary of feed intake and body-weight change of male and female rats fed a $\mathrm{Zn}$-deficient diet

The feed intake and body-weight change of male and female rats fed a $\mathrm{Zn}$-deficient diet were estimated daily. After four-days of feeding the $\mathrm{Zn}$-deficient diet, rats showed typical signs of $\mathrm{Zn}$ deficiency such as anorexia and reduced growth as compared to the control rats. The body weight of the control rats increased linearly under the experimental conditions, while that of the $\mathrm{Zn}$-deficient diet group was cyclically retarded. The feed intake of the male rats fed the control $(n=24)$ and $\mathrm{Zn}$-deficient diets $(n=38)$ during the experimental period was $15.4 \pm$ 0.4 and $10.1 \pm 0.2 \mathrm{~g} / \mathrm{d}$, respectively $(p<0.001)$, and the body-weight change in the respective groups was $5.3 \pm 0.1$ and $1.8 \pm 0.2 \mathrm{~g} / \mathrm{d}$, respectively $(p<0.001)$. The feed intake of the female rats fed the control $(n=5)$ and $\mathrm{Zn}$-deficient diets $(n=5)$ was $12.6 \pm 0.4$ and $7.8 \pm 0.3 \mathrm{~g} / \mathrm{d}$, respectively $(p<0.001)$. The weight gain in the female rats in the respective groups throughout the experimental period was $3.3 \pm 0.2$ and $1.2 \pm 0.2 \mathrm{~g} / \mathrm{d}$, respectively $(p<0.001)$.

The feed intake and body-weight change in the previous 24-h period of each male and female rat fed the $\mathrm{Zn}$-deficient diet fit well to a Cosinor curve, as shown in our preliminary paper (14). The representative patterns of feed intake and body-weight change in $\mathrm{Zn}$-deficient rats are illustrated in Fig. 1, a and b, respectively, together with the simulation data for feed intake and body-weight change. The experimental data were fitted to a cosine wave with very high correlation. The mean values with standard errors of $M, A, \tau$ and $\phi$ are summarized in Table 2. The coefficients of variation of $M, A, \tau$ and $\phi$ for the cycle of feed intake of male rats were 15, 31, 8 and 59\%, respectively, and those of female rats were 7.5, 13.2, 6.8 and $7.4 \%$, respectively. The calculated values of $M, A, \tau$ and $\phi$ for the cycle of 

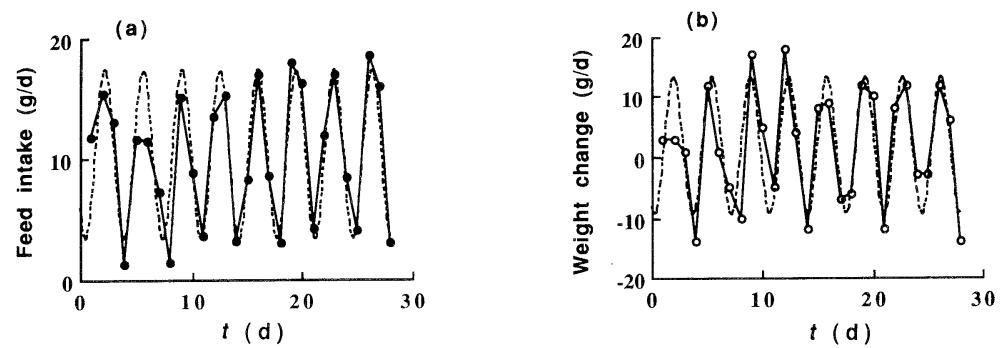

Fig. 1. Pattern of cyclic variation of feed intake (a) and body-weight change (b) of a representative male rat fed a $\mathrm{Zn}$-deficient diet. Each point represents the feed intake $(a, \bullet)$ or body-weight change $(b, O)$ for the previous 24 -h period. Data were analyzed by the Cosinor method. The curve with best fit obtained with computer-generated cosine curves (---). Feed intake and body-weight change at day $t$ are $F=10.4 \pm 7.0 \cos (2 \pi t / 3.5+2.3)$ and $\Delta B=1.9 \pm 11.3 \cos (2 \pi t / 3.5+$ 2.7), respectively.

Table 2. Mean values of parameters in Cosinor analysis of feed intake and bodyweight change in the previous 24 -h period for male and female rats.

\begin{tabular}{lcccc}
\hline & $\begin{array}{c}\text { Mesor }(M) \\
(\mathrm{g} / \mathrm{d})\end{array}$ & $\begin{array}{c}\text { Amplitude }(A) \\
(\mathrm{g} / \mathrm{d})\end{array}$ & $\begin{array}{c}\text { Period }(\tau) \\
(\mathrm{d})\end{array}$ & $\begin{array}{c}\text { Acrophase }(\phi) \\
\text { (radian) }\end{array}$ \\
\hline Feed intake & & & & \\
$\quad$ Male & $10.0 \pm 0.3$ & $4.4 \pm 0.2$ & $3.5 \pm 0.05$ & $3.5 \pm 0.3$ \\
$\quad$ Female & $7.9 \pm 0.3$ & $4.4 \pm 0.3$ & $3.6 \pm 0.12$ & $3.6 \pm 1.0$ \\
Body-weight change & & & & \\
$\quad$ Male & $1.8 \pm 0.2$ & $8.1 \pm 0.4$ & $3.4 \pm 0.05$ & $3.7 \pm 0.3$ \\
$\quad$ Female & $1.2 \pm 0.1$ & $8.5 \pm 0.7$ & $3.6 \pm 0.09$ & $3.1 \pm 0.8$ \\
\hline
\end{tabular}

Each value is the mean \pm SE. Feed intake $(F)$ or body-weight change $(\Delta B)$ in the previous 24 -h period at day $t: F$ (or $\Delta B)=M+A \cos (2 \pi t / \tau+\phi)$. Values are presented as the average $\pm \mathrm{SE}$ from 38 male or 5 female rats fed a $\mathrm{Zn}$-deficient diet.

body-weight change of male rats were 50, 30, 8 and $61 \%$, respectively, and those of female rats were 22.7, 17.3, 5.0 and 50.9\%, respectively. All the data from 38 male rats and 5 female rats were also analyzed by the Cosinor method. The feed intake and body-weight change fit a cosine curve (Table 3 ). The periods of the cycles of feed intake and body-weight change of the male and female rats varied from 3.3 to $3.4 \mathrm{~d}$ and were about same as the average value of the cycles calculated for each rat (Tables 2 and 3). However, the values of amplitude for the feed intake and body-weight change cycles calculated from all of the data of the male or female rats were much lower than those of the average values calculated for each rat.

\section{Serum alkaline phosphatase and $\mathrm{Zn}$ content in $\mathrm{Zn}$-deficient rats}

The serum alkaline phosphatase activity in the male rats fed the control $(n=$ $24)$ and $\mathrm{Zn}$-deficient diets $(n=25)$ was $9.94 \pm 2.29$ and $4.91 \pm 2.17 \mathrm{nmol} / \mathrm{min}$ per $\mathrm{mg}$ 
Table 3. Cosinor analysis from all the data for male and female rats fed a $\mathrm{Zn}$ deficient diet for feed intake and body-weight change.

\begin{tabular}{lccccccc}
\hline & $\begin{array}{c}M \\
(\mathrm{~g} / \mathrm{d})\end{array}$ & $\begin{array}{c}A \\
(\mathrm{~g} / \mathrm{d})\end{array}$ & $\begin{array}{c}\tau \\
(\mathrm{d})\end{array}$ & $\begin{array}{c}\phi \\
(\text { radian })\end{array}$ & $r$ & $t$ & $p$ \\
\hline $\begin{array}{l}\text { Feed intake } \\
\quad \text { Male }\end{array}$ & $10.0 \pm 0.1$ & $1.2 \pm 0.2$ & $3.3 \pm 0.04$ & $2.9 \pm 0.3$ & 0.179 & 5.903 & $<0.0001$ \\
$\quad \begin{array}{l}\text { Female } \\
\text { Body-weight change } \\
\quad \text { Male }\end{array}$ & $7.9 \pm 0.3$ & $1.8 \pm 0.4$ & $3.3 \pm 0.05$ & $0.3 \pm 0.5$ & 0.331 & 4.113 & $<0.0001$ \\
$\quad$ Female & $1.8 \pm 0.3$ & $1.8 \pm 0.4$ & $3.3 \pm 0.04$ & $4.1 \pm 0.4$ & 0.156 & 5.090 & $<0.0001$ \\
& $1.3 \pm 0.6$ & $3.0 \pm 0.9$ & $3.4 \pm 0.07$ & $1.7 \pm 0.6$ & 0.284 & 3.466 & $<0.001$ \\
\hline
\end{tabular}

Each value is the mean \pm SD. Feed intake $(F)$ or body-weight change $(\Delta B)$ in the previous 24-h period at day $t: F$ (or $\Delta B)=M+A \cos (2 \pi t / \tau+\phi$ ). Cosinor analysis was conducted with all the data from 38 male and 5 female rats fed a $\mathrm{Zn}$-deficient diet.

protein, respectively $(p<0.001)$. The enzyme activity in the female rats fed the control $(n=5)$ and Zn-deficient diets $(n=5)$ was $7.68 \pm 0.66$ and $4.02 \pm 0.79$ $\mathrm{nmol} / \mathrm{min}$ per $\mathrm{mg}$ protein, respectively $(p<0.01)$. When we simulated the value of $\cos (2 \pi t / \tau+\phi)$ on the final day in the formula for feed intake and body-weight change in the male rats fed the $\mathrm{Zn}$-deficient diet, we could not find any relationship with the cosine value or serum alkaline phosphatase activity, respectively $(r=0.000$, $\mathrm{df}=23, \mathrm{NS} ; r=0.134, \mathrm{df}=23, \mathrm{NS}$, respectively).

The serum $\mathrm{Zn}$ content in the control and $\mathrm{Zn}$-deficient groups of male rats was $2.58 \pm 0.09$ and $1.00 \pm 0.21 \mathrm{nmol} / \mathrm{min}$ per $\mathrm{mg}$ protein, respectively $(\mathrm{df}=22, p<$ $0.001)$. However, there was no correlation between the above cosine values and the serum $\mathrm{Zn}$ content (feed intake: $r=0.084$, $\mathrm{df}=16$, NS; weight change: $r=0.095$, $\mathrm{df}=16, \mathrm{NS})$.

Relationships among parameters of the cycles for feed intake and body-weight change of male rats fed a $\mathrm{Zn}$-deficient diet

The values of correlation among parameters for the cycles of feed intake and body-weight change in male rats fed the $\mathrm{Zn}$-deficient diet are presented in Table 4. The cyclical periods of both the feed intake and body-weight change were significantly correlated with the respective mesor. In the cycle of body-weight change, the amplitude $(A)$ also had a significant negative correlation to the mesor $(M)$. The values of $A$ for the cycles of feed intake and body-weight change had a positive correlation to the correlation value of their own simulated cycles $(r=0.829, \mathrm{df}=36$, $p<0.0001$ and $r=0.6964, \mathrm{df}=36, p<0.0001$, respectively).

Correlation of each parameter between feed intake and body-weight change cycles of rats fed a Zn-deficient diet

The correlation of parameters between feed intake and body-weight change cycles of rats fed the $\mathrm{Zn}$-deficient diet were analyzed. Each parameter $(M, A, \tau$ and $\phi$ ) of the cycle for weight change had a highly significant correlation to the 
Table 4. Correlation coefficients among parameters of feed intake and body-weight change cycles of $\mathrm{Zn}$-deficient male rats.

\begin{tabular}{ccccc}
\hline a) & Feed intake cycle & $\boldsymbol{A}$ & $\tau$ & $\phi$ \\
\hline $\boldsymbol{M}$ & -0.077 & $0.499^{* *}$ & -0.071 \\
& $\boldsymbol{T}$ & & -0.089 & -0.259 \\
& $\tau$ & & 0.095 \\
\hline b) & Body-weight change cycle & $\boldsymbol{A}$ & $\tau$ & $\phi$ \\
\hline $\boldsymbol{M}$ & $-0.399^{*}$ & $0.321^{*}$ & -0.089 \\
& $\boldsymbol{}$ & 0.000 & -0.245 \\
& & & 0.000 \\
\hline
\end{tabular}

Feed intake $(F)$ or body-weight change $(\Delta B)$ in the previous 24 -h period at day $t$ : $F(\Delta B)=M+A \cos (2 \pi t / \tau+\phi)$.

Values are correlation coefficients among parameters and calculated from 38 individual $\mathrm{Zn}$-deficient rats. ${ }^{* *} p<0.01,{ }^{*} p<0.05$.

Table 5. Correlation between each pair of parameters of feed intake and bodyweight change cycles of $\mathrm{Zn}$-deficient male rats.

\begin{tabular}{ccccc}
\hline & \multicolumn{4}{c}{ Feed intake } \\
\cline { 2 - 5 } & $M$ & $A$ & \multicolumn{1}{c}{$\tau$} & $\phi$ \\
\hline Body-weight change & & & & \\
$M$ & $0.846^{* * *}$ & -0.126 & $0.501^{* *}$ & -0.200 \\
$A$ & $-0.345^{*}$ & $0.771^{* * *}$ & -0.167 & -0.100 \\
$\tau$ & $0.383^{*}$ & 0.071 & $0.925^{* * *}$ & -0.032 \\
$\phi$ & -0.045 & $-0.330^{*}$ & 0.000 & $0.452^{* *}$ \\
\hline
\end{tabular}

Feed intake $(F)$ or body-weight change $(\Delta B)$ in the previous 24-h period at day $t$ : $F(\Delta B)=M+A \cos (2 \pi t / \tau+\phi)$. Values are correlation coefficients between each pair of parameters and are calculated from 38 individual $\mathrm{Zn}$-deficient male rats. ${ }^{* * *} p<$ $0.001,{ }^{*} p<0.01,{ }_{p}<0.05$.

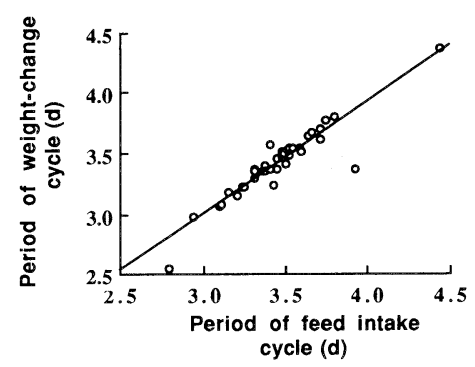

Fig. 2. Correlation between period of feed intake cycle and period of weight-change cycle of male rats fed a $\mathrm{Zn}$-deficient diet. $y=0.182+0.939 x, r=0.925, \mathrm{df}=36$, $p<0.001$. 

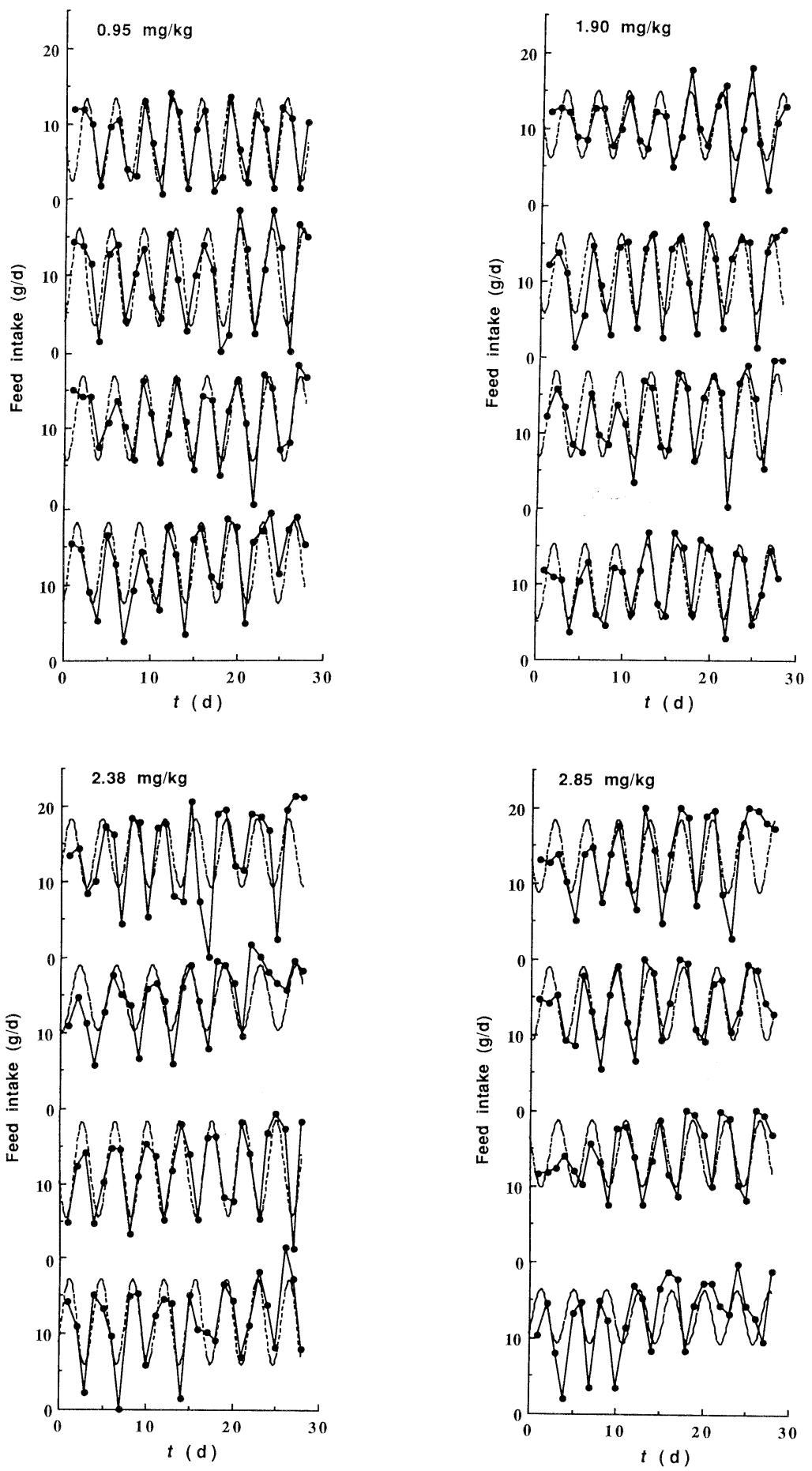

J Nutr Sci Vitaminol 

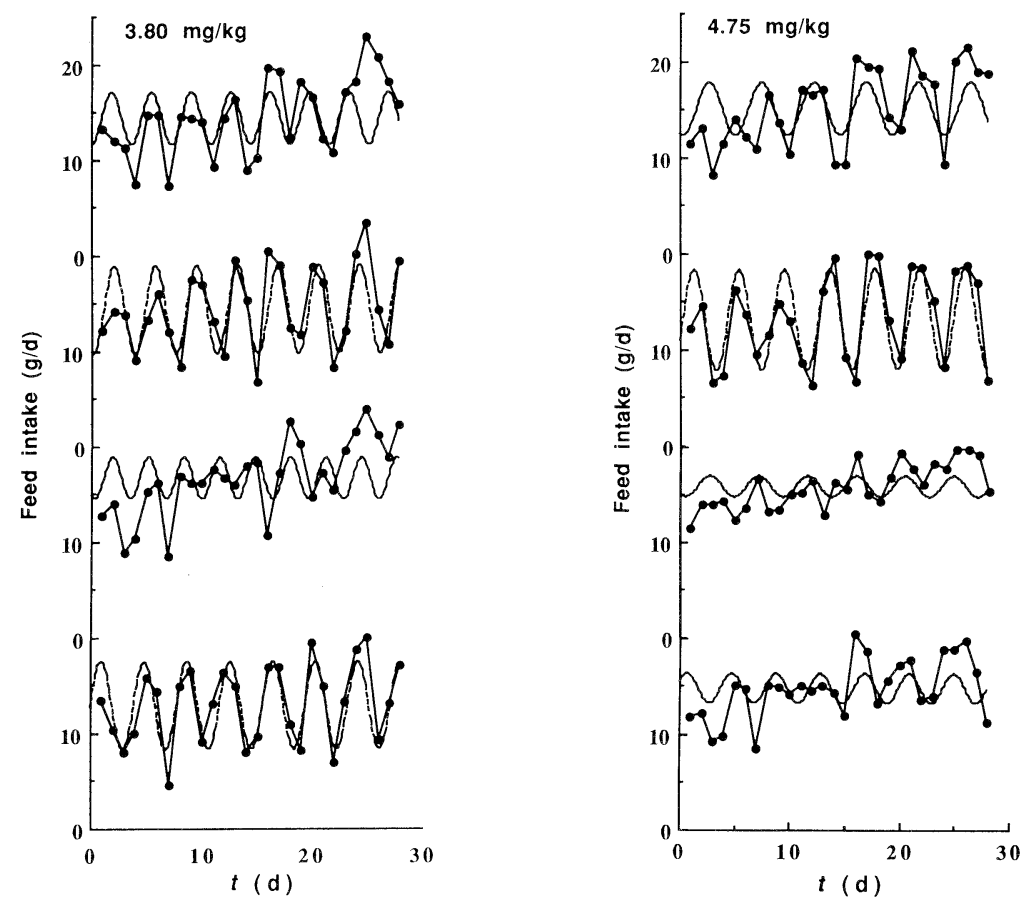

Fig. 3. Effect of $\mathrm{Zn}$ supplementation on the patterns of cyclic variation of feed intake. Each rat was fed the experimental diet for 28 days under the conditions described in Materials and Methods. The diets with $\mathrm{Zn}$ contents of $0.95,1.90$, $2.38,2.85,3.80$ and $4.75 \mathrm{mg} / \mathrm{kg}$ correspond to supplemental $\mathrm{Zn}$ at the ratios of 0 , $0.95,1.43,1.90,2.85$ and $3.80 \mathrm{mg} / \mathrm{kg}$ of $\mathrm{Zn}$-deficient basal diet. Each point represents the feed intake $(\bullet)$ for the previous 24 -h period and the curve $(---)$ with best fit obtained with the parameters. Feed intake at day $t: F=M+$ $A \cos (2 \pi t / \tau+\phi)$.

corresponding parameter of the cycle for feed intake (Table 5 and Fig. 2). The period of feed intake cycle and body-weight change had the highest correlation coefficient. From these results, we conjectured that the cycle of body-weight change may well reflect that of feed intake. Therefore, the period of the feed intake cycle may produce a high correlation to the mesor of the body-weight change cycle, because the former has a good correlation to its own mesor.

Effect of Zn supplementation on feed intake and body-weight change cycles of male rats fed a $\mathrm{Zn}$-deficient diet

The daily feed intake and body-weight change of male rats fed supplemental $\mathrm{Zn}$ in the $\mathrm{Zn}$-deficient basal diet were estimated for 28 days, and the best fit curves were shown in Figs. 3 and 4. The supplementation of $\mathrm{Zn}$ up to $3.8 \mathrm{mg} / \mathrm{kg}$ of the Zn-deficient diet maintained a significant cyclical feed intake and body-weight

Vol 43, No 3, 1997 

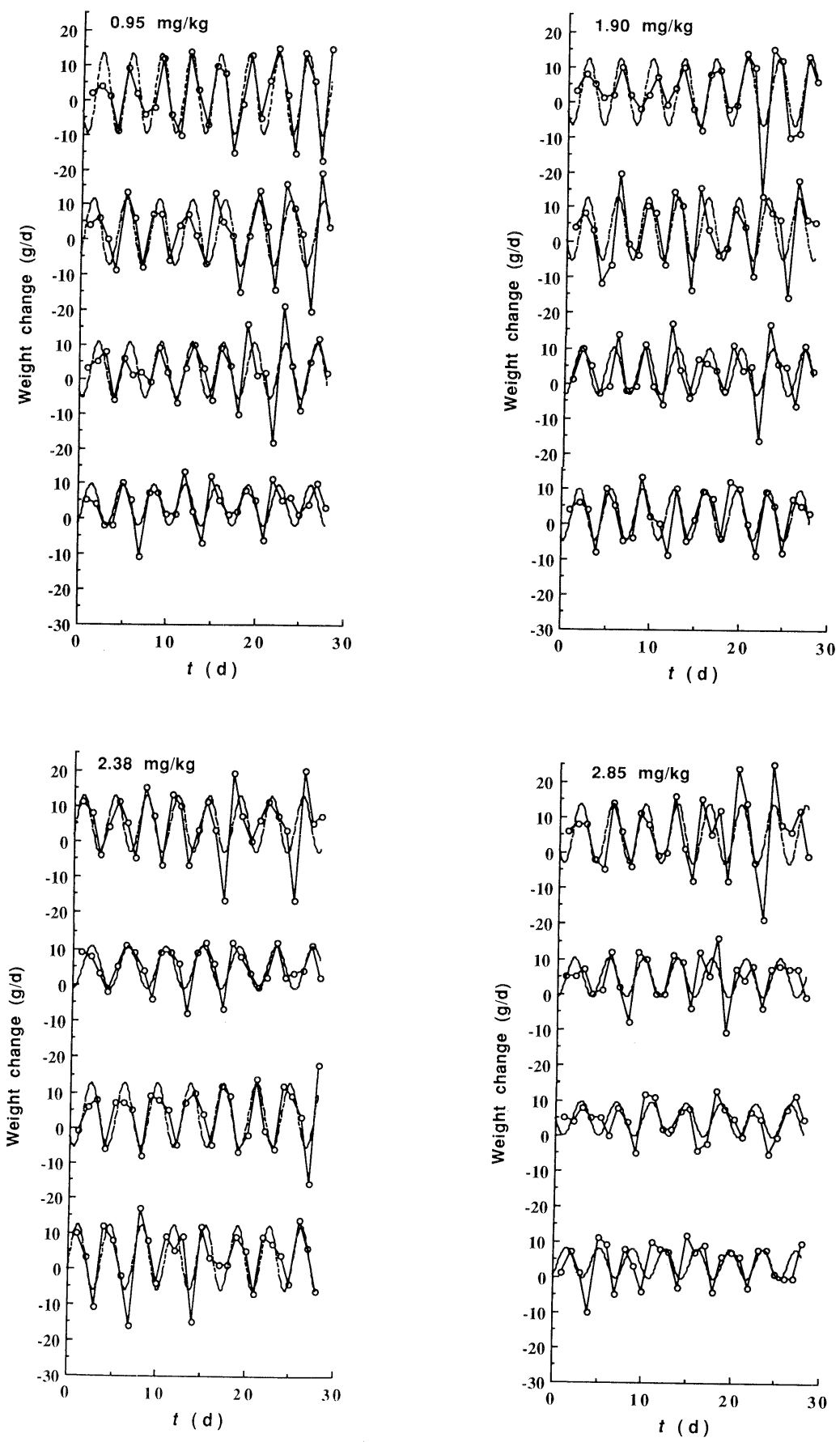

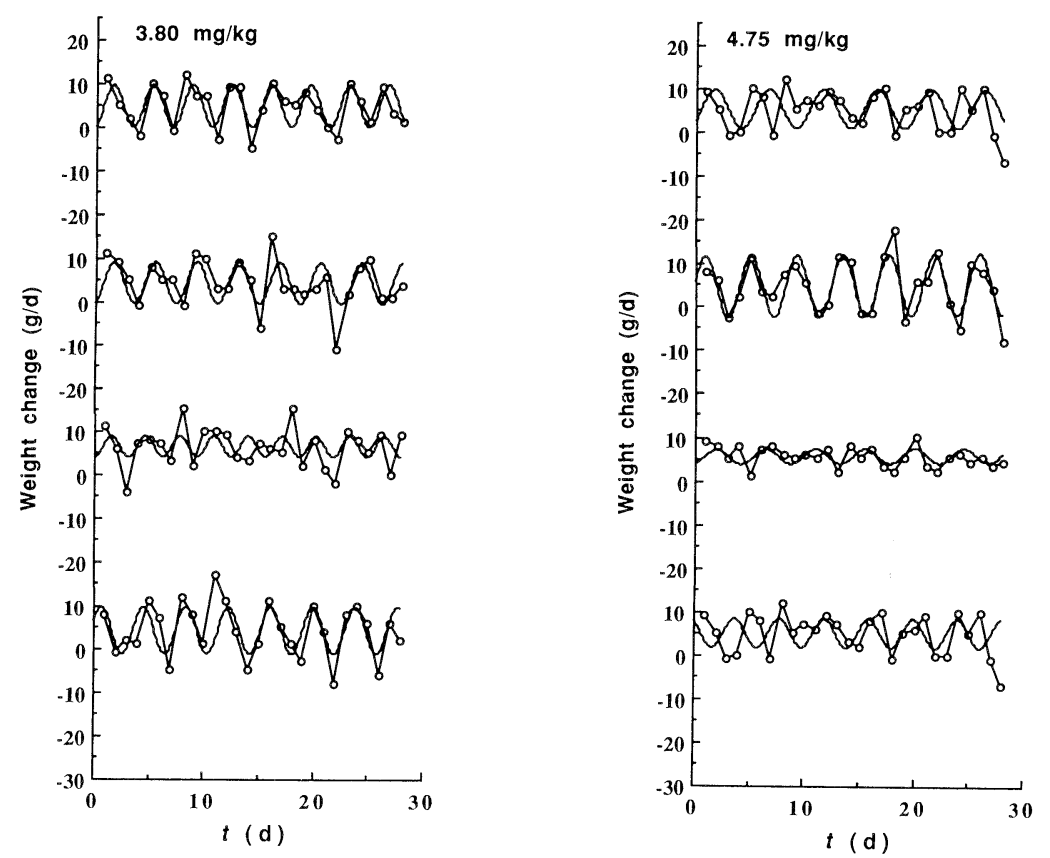

Fig. 4. Effect of $\mathrm{Zn}$ supplementation on the patterns of cyclic variation in bodyweight change. Each rat was fed the experimental diet for $28 \mathrm{~d}$ under the conditions described in Materials and Methods. The diets with $\mathrm{Zn}$ contents of $0.95,1.90,2.38,2.85,3.80$ and $4.75 \mathrm{mg} / \mathrm{kg}$ correspond to the supplemental $\mathrm{Zn}$ at the ratios of $0,0.95,1.43,1.90,2.85$ and $3.80 \mathrm{mg} / \mathrm{kg}$ of $\mathrm{Zn}$-deficient basal diet. Each point represents the body-weight change $(O)$ for the previous 24-h period and the curve (---) with best fit obtained with the parameters. Body-weight change at day $t: \Delta B=M+A \cos (2 \pi t / \tau+\phi)$.

change. In the group that received a $\mathrm{Zn}$ supplementation of $4.75 \mathrm{mg} / \mathrm{kg}$ diet, the feed intake and body-weight change of two rats were significantly correlated to a cosine curve, but those of the other two rats were only weakly correlated $(0.05<$ $p<0.10)$. The average values with standard errors of the four parameters of the feed intake and body-weight change cycles for the different contents of $\mathrm{Zn}$ in the diet are summarized in Table 6. The values of the mesor of feed intake and body-weight change cycles increased as the $\mathrm{Zn}$ content of the diet increased, but the value of the amplitude for the two cycles decreased. The acrophase of the feed intake cycle showed no significant difference with the supplementation with $\mathrm{Zn}$ (Table 6).

We evaluated the parameters of both cycles with daily $\mathrm{Zn}$ intake, which were estimated from the mesor of individual feed intake cycles. The mesor, amplitude and period values of the feed intake cycle showed a close relationship to $\mathrm{Zn}$ intake (Fig. 5). These three parameters of the body-weight change cycle were also significantly correlated to $\mathrm{Zn}$ intake $(r=0.828, p<0.001, r=-0.783, p<0.001$ and 


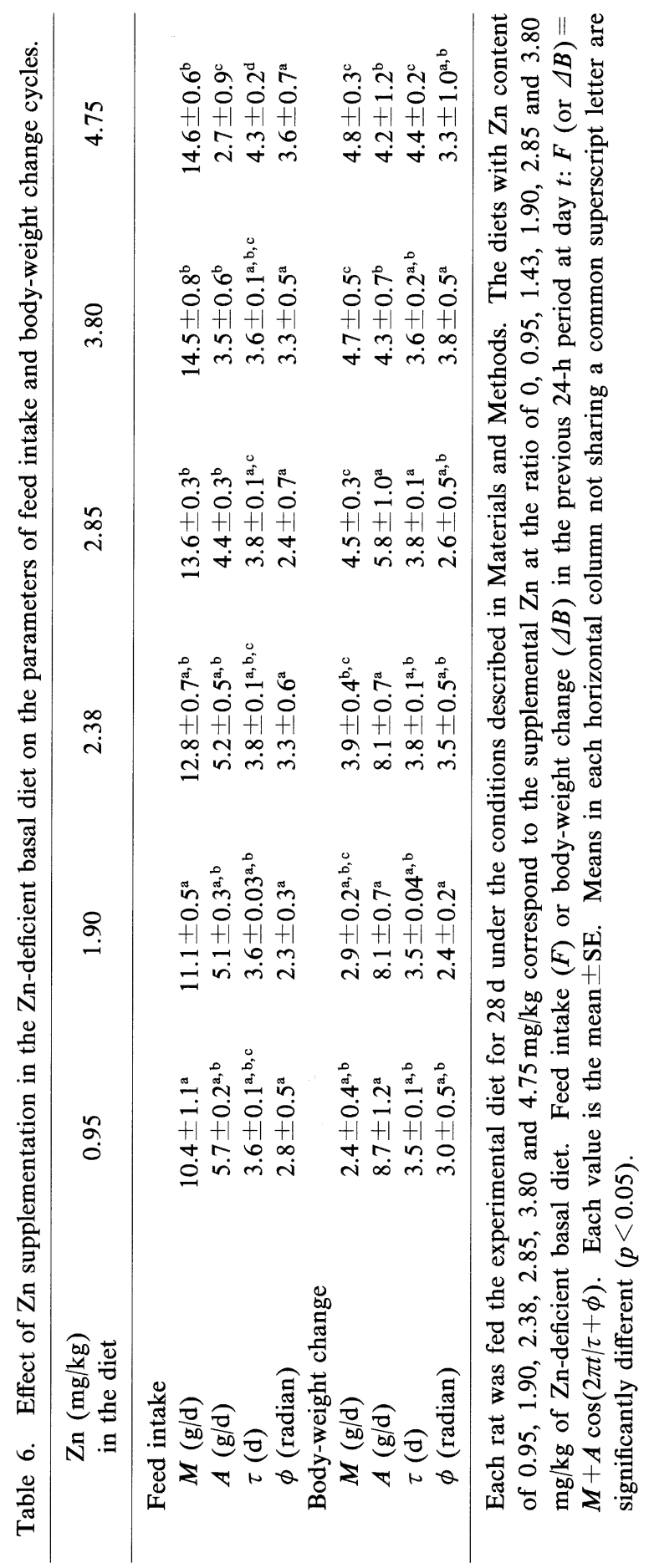



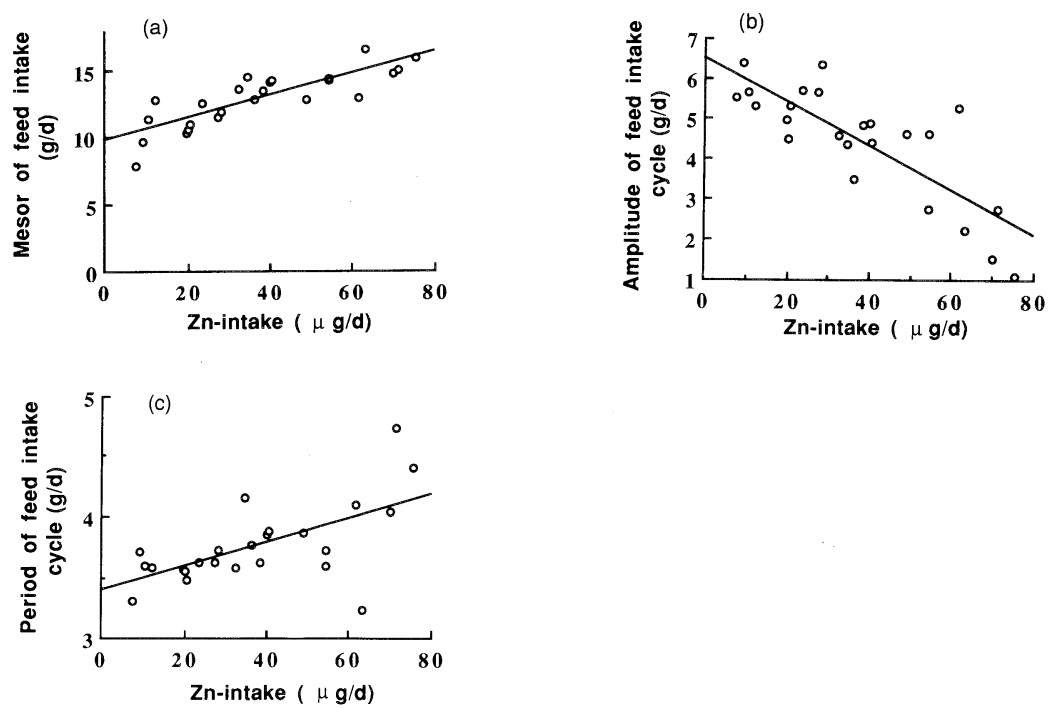

Fig. 5. Correlation between the mesor, amplitude and period of the feed intake cycle and $\mathrm{Zn}$ intake. The parameters of the feed intake cycle were for rats fed a $\mathrm{Zn}$-deficient basal diet supplemented with different quantities of $\mathrm{Zn}$. $\mathrm{Zn}$ intake was estimated from the mesor of the feed intake cycles of individual rats. The relationships for the mesor (a), amplitude (b) or period (c) of the feed intake cycles with $\mathrm{Zn}$ intake were $y=9.71+0.0835 x(r=0.830, \mathrm{df}=22, p<0.001), y=$ $6.52-0.0554 x(r=-0.804, \mathrm{df}=22, p<0.001)$ and $y=3.39+0.00988 x \quad(r=0.613$, $\mathrm{df}=22, p<0.01)$, respectively.

Table 7. Apparent values of parameters on feed intake and body-weight change cycles of rats fed a $\mathrm{Zn}$-free diet.

\begin{tabular}{lcc}
\hline & Feed intake cycle & Body-weight change cycle \\
\hline$M(\mathrm{~g} / \mathrm{d})$ & $9.7 \pm 0.1$ & $2.2 \pm 0.1$ \\
$A(\mathrm{~g})$ & $6.5 \pm 0.1$ & $10.0 \pm 0.1$ \\
$\tau(\mathrm{d})$ & $3.4 \pm 0.02$ & $3.3 \pm 0.03$
\end{tabular}

Each value is the mean \pm SE. Feed intake $(F)$ or body-weight change $(\Delta B)$ in the previous 24-h period at day $t: F(\Delta B)=M+A \cos (2 \pi t / \tau+\phi)$. Values were simulated from the pseudo first-order kinetics between each parameter and the concentration of $\mathrm{Zn}$ intake calculated from the mesor of the feed intake cycle. The acrophase $(\phi)$ of both cycles was independent of $\mathrm{Zn}$ intake.

$r=0.607, p<0.01$, respectively) (not shown).

When the rats fed the $\mathrm{Zn}$-free diet assumed to have a cosine curve on daily feed intake and body-weight change, the apparent values of the mesor, amplitude and period for both cycles were calculated from the intercept of the vertical axis on the above relationship and stated in Table 7. However, the acrophase of the feed intake and weight change cycles had no assignment for the relationship to $\mathrm{Zn}$ intake. 
Therefore, the acrophase of both cycles may be merely chance reflections of variations in the rate of initial onset of the deficiency and of no biological significance.

The concentrations of $\mathrm{Zn}$ intake given the half-maximal values of the amplitude of the feed intake and weight change cycles were $56 \pm 1$ and $53 \pm 1 \mu \mathrm{g} / \mathrm{d}$, respectively.

\section{DISCUSSION}

Male and female rats fed a Zn-deficient diet showed a cyclical pattern in the change of both feed intake and body weight. The data of feed intake and body-weight change for all the rats fed the $\mathrm{Zn}$-deficient diet were fitted to a cosine curve. However, when we analyzed the periodic feed intake using the data for individual rats, the four parameters of the cycle showed values different from those obtained by the former method. The coefficients of variation for the acrophase and amplitude of the feed intake cycle calculated by the latter method were 45.4 and $30.8 \%$, respectively. It is suggested that there are individual variations in the rate of initial onset of the deficiency and in response to the $\mathrm{Zn}$-deficient diet. The same results were also found in the investigation of the weight change cycle of the Zn-deficient rats.

The parameters of these cycles show characteristic properties. First, the values of the 4 parameters $M, A, \tau$ and $\phi$ for the cycle of feed intake had significant relationships with the corresponding parameters for the cycle of body-weight change. These results suggest a close relation between feed intake and body-weight change. The value of $\tau$ for the feed intake cycle was related to that of $M$ for that cycle, but it had no relation to the initial weight before administration of the experimental $\mathrm{Zn}$-deficient diet. Therefore, a rat that enters a severe deprivation state due to a Zn-deficient diet shows a shorter period in the feed intake cycle, while a rat that tolerates the diet has a longer one. The values of $\boldsymbol{A}$ for the cycles of feed intake as well as body-weight change were well correlated to their own correlation coefficients of their cycles. Moreover, the ratios of $\boldsymbol{A}$ to $\boldsymbol{M}$ for both cycles of feed intake and body-weight change were high, 0.45 and 8.12 , respectively. This indicates that, among rats fed the $\mathrm{Zn}$-deficient diet, the feed intake pattern of a rat with a high $A$ fit the cosine curve well. The periods of the two cycles have the smallest coefficients of variation among the parameters.

A cyclical pattern of intake was also found in the female rats fed a $\mathrm{Zn}$-deficient diet, as previously published (1). In the female rats, the mesor value of the feed intake cycle was significantly lower than that of the male rats, but the cyclical periods of the feed intake cycles of the male and female rats had the same values. These results suggest that sex hormones do not affect the cycles of feed intake and body-weight change of rats fed a $\mathrm{Zn}$-deficient diet. $\mathrm{Zn}$ deficiency impairs growth by reducing feed intake and the anabolic response to food with increased catabolic response to the reduced intake, in which corticosterone may also play a role (5). 
Recently, it was proposed that the growth retardation seen in $\mathrm{Zn}$-deficient states may be mediated through reduced serum-like growth factor-1 production (22). However, these factors could not account for the 3.5-d cycle of the feed intake.

From the perusal of the feed intake of male rats fed the $\mathrm{Zn}$-deficient diet, it can be seen that the maximum daily feed intake was the same as the average level of the control rats. The maximum daily body-weight change in the $\mathrm{Zn}$-deficient rats was significantly greater than that of the control rats. These results suggest that the feed intake of rats fed a $\mathrm{Zn}$-deficient diet at a moderate level can more effectively reflect their body-weight gain than in the case of the control rats. The rats consumed the $\mathrm{Zn}$-deficient diet at the same volume as the control rats, but then become anorexic and decrease their feed intake. After an elevated feed intake by the rats eating a $\mathrm{Zn}$-deficient diet, a toxic metabolic product may accumulate or a state of metabolic deprivation may continue, reaching deleterious concentrations or proportions that inhibit appetite, as shown by Chesters and Quarterman (8). These metabolites disappear within one half-time $(1.7 \pm 0.02 \mathrm{~d})$ of the feed intake cycle and the appetite of the $\mathrm{Zn}$-deficient rats recovers. The time until disappearance of the toxic metabolite is constant, so the feed intake through the experimental period in $\mathrm{Zn}$-deficient diet would fit a cosine curve. The coefficient of variation of amplitude for the feed intake cycle was four times greater than that of the period. These phenomena suggest that the responsiveness and capacity to tolerate a $\mathrm{Zn}$-deficient diet differ from rat to rat.

The cyclical patterns of feed intake and of body-weight change in rats fed a $\mathrm{Zn}$-deficient diet are likely to be related to the $\mathrm{Zn}$ contents in the diet (1). In our study, the mean values of feed intake and body-weight change increased with the increase in $\mathrm{Zn}$ content of the diet, while the amplitudes of both cycles declined and the periods were elongated. Moreover, the daily intake of $\mathrm{Zn}$ given a half-maximal value of the amplitude of the feed intake cycle was $56 \pm 1 \mu \mathrm{g}$ per rat. These results suggest the $\mathrm{Zn}$ acts as a sensitive effector for rats, with a cosine curve of feed intake under $\mathrm{Zn}$-deficient conditions. The supplementation of $\mathrm{Zn}$ up to $3.80 \mathrm{mg} / \mathrm{kg}$ of the $\mathrm{Zn}$-deficient basal diet $(4.75 \mathrm{mg} / \mathrm{kg} \mathrm{Zn}$ in the diet) disrupted the correlation to the cosine curve for feed intake and body-weight change.

The feed intake of rats fed a $\mathrm{Zn}$-deficient 5\%-protein diet had no cyclic pattern and showed the same pattern as that of rats fed a $\mathrm{Zn}$-supplemented 5\%-protein diet (10). Protein in a Zn-deficient diet may also be a key factor affecting cyclical feed intake patterns in rats. Recently, Golub et al. (23) noted that $\mathrm{Zn}$ itself initiates cyclic feeding and that the cycle is an artifact of the laboratory situation in which a constant supply of only one food is available. However, their hypotheses do not explain why the feeding cycle through one month has a definite period of $3.5 \pm$ $0.05 \mathrm{~d}$. The effectors acting on the feed intake cycle of rats fed a $\mathrm{Zn}$-deficient diet await further investigation. 


\section{REFERENCES}

1) Williams RB, Mills CF. 1970. The experimental production of zinc deficiency in the rat. Br J Nutr 24: 989-1003.

2) Golden BE. 1988. Zinc in cell division and tissue growth: physiological aspects. In: Zinc in Human Biology (Mills CF, ed), p 119-128. Springer Verlag, Berlin.

3) Wallwork JC, Fosmire GJ, Sandstead HH. 1981. Effect of zinc deficiency on appetite and plasma amino acid concentrations in the rat. Br J Nutr 45: 127-136.

4) Giugliano R, Millward DJ. 1984. Growth and zinc homeostasis in the severely Zn-deficient rat. Br J Nutr 52: 545-560.

5) Giugliano R, Millward DJ. 1987. The effects of severe zinc deficiency on protein turnover in muscle and thymus. Br J Nutr 57: 139-155.

6) Droke EA, Spears JW, Armstrong JD, Kegley EB, Simson RB. 1993. Dietary zinc affects serum concentrations of insulin and insulin-like growth factor $\mathrm{I}$ in growing lambs. J Nutr 123: 13-19.

7) Mills CF, Quarterman J, Chesters JK, Williams RB, Dalgarno AG. 1969. Metabolic role of zinc. Am J Clin Nutr 22: 1240-1249.

8) Chesters JK, Quarterman J. 1970. Effects of zinc deficiency on food intake and feeding patterns of rats. Br J Nutr 24: 1061-1069.

9) Williams RB. 1972. Intestinal alkaline phosphatase and inorganic pyrophosphatase activities in the zinc-deficient rat. Br J Nutr 27: 121-130.

10) Chesters JK, Will M. 1973. Some factors controlling food intake by zinc-deficient rats. Br J Nutr 30: 555-566.

11) Kramer TR, Briske-Anderson M, Johnson SB, Holman RT. 1984. Influence of reduced food intake on polyunsaturated fatty acid metabolism in zinc-deficient rats. $J$ Nutr 114: $1224-1230$.

12) Quinn PB, Cremin FM, O'sullivan VR, Hewedi FM, Bond RJ. 1990. The influence of dietary folate deficient rats. Br J Nutr 64: 233-243.

13) Rains TM, Shay NF. 1995. Zinc status specifically changes preferences for carbohydrate and protein in rats selecting from separate carbohydrate-, protein-, and fatcontaining diets. J Nutr 125: 2874-2879.

14) Tamaki N, Fujimoto-Sakata S, Kikugawa M, Kaneko M, Onosaka S, Takagi T. 1995. Analysis of cyclic feed intake in rats fed on a zinc-deficient diet and the level of dihydropyrimidinase (EC 3.5.2.2). Br J Nutr 73: 711-722.

15) Kasarkis EJ, Schura A. 1982. Serum alkaline phosphatase after treatment of zinc deficiency in humans. Am J Clin Nutr 33: 2609-2612.

16) Weismann K, Hoyer H. 1985. Serum alkaline phosphatase and serum zinc levels in the diagnosis and exclusion of zinc deficiency in man. Am J Clin Nutr 41: 1214-1219.

17) Bessey OA, Lowry OH, Brock MJ. 1946. A method for rapid determination of alkaline phosphatase with 5 cubic millimeters of serum. J Biol Chem 164: 321-329.

18) Lowry OH, Rosebrough NJ, Farr AL, Randall RJ. 1951. Protein measurement with the Folin phenol reagent. $J$ Biol Chem 193: 265-275.

19) Halberg F, Johnson EA, Nelson W, Runge W, Sothern R. 1972. Autorhythmometryprocedures for physiologic self-measurements and their analysis. Physiol Teacher 1: 111. 
20) Marquardt DW. 1963. An algorithm for least-squared estimation of nonlinear parameters. J Soc Indust Appl Math 11: 431-441.

21) Yamaoka K, Tanigawara Y, Nakagawa T, Uno T. 1981. A pharmacokinetic analysis program (MULTI) for microcomputer. J Pharmacobio-Dyn 4: 879-885.

22) Dorup I, Flyvbjerg A, Everts MA, Clausen T. 1991. Role of insulin-like growth factor1 and growth hormone in growth inhibition induced by magnesium and zinc deficiencies. Br J Nutr 66: 505-521.

23) Golub MS, Keen CL, Gershwin ME, Hendickx AG. 1995. Developmental zinc deficiency and behavior. $J$ Nutr 125: 2263S-2271S. 